\title{
Estereotipos masculinos y femeninos en los zoologismos fraseológicos españoles y checos ${ }^{1}$
}

\author{
Pavla ŠKVÁROVÁ \\ Petr ŠLECHTA \\ Univerzita Palackého v Olomouci \\ Universidad de Granada \\ pavla.skvarova@hotmail.com \\ petr.slechta@centrum.cz
}

Recibido: Mayo de 2014

Aceptado: Diciembre de 2014

\section{Resumen}

El trabajo pretende mostrar los estereotipos de hombre y mujer en la sociedad occidental según los estudios de género para, más tarde, comprobar si dichos estereotipos se reflejan en la fraseología checa y española relativa a animales, es decir, en los zoologismos. El análisis se sustenta en las teorías de la lingüística cognitiva acerca de la metáfora conceptual y del lenguaje figurado convencional. Las conclusiones muestran una clara discriminación de ambos géneros en el lenguaje, siendo el femenino más afectado que el masculino.

Palabras clave: fraseología, zoologismos, lenguaje figurado convencional, lingüística de género, metáfora conceptual.

\section{The Differences in Gender in the Czech and Spanish Zoologisms}

\begin{abstract}
The paper aims to show the stereotypes of men and women in Western society according to gender studies to later determine whether those stereotypes are reflected in the Czech and Spanish phraseology concerning animals, i.e. in zoologisms. The analysis is based on theories of cognitive linguistics on conceptual metaphor and conventional figurative language. The findings show a clear discrimination of both genders, the feminine being more affected.
\end{abstract}

Key words: phraseology, zoologisms, conventional figurative language, gender linguistics, conceptual metaphor.

SUMARIO: 1. Introducción; 2. Principios metodológicos; 3. Análisis; 4. Conclusiones; 5. Referencias bibliográficas.

\footnotetext{
1 La investigación aquí presentada ha sido posible gracias a la financiación por parte de un proyecto de investigación concedido por la Facultad de Filosofía y Letras de la Universidad Palacký de Olomouc "Imagen lingüística del mundo en la fraseología: reflexión de las diferencias de género en español, checo e inglés" ("Jazykový obraz světa ve frazeologii: přirozený rod a jeho reflexe ve španělštině, češtině a angličtině” - IGA 432101311), dirigida por el Dr. Enrique Gutiérrez Rubio. A su vez, se enmarca dentro de un proyecto de investigación de mayores dimensiones que pretende analizar las afinidades y divergencias en la imagen lingüística del mundo que subyace en la fraseología de cuatro lenguas europeas: alemán, checo, español e inglés (cfr. GUTIÉRREZ RUBIO 2012a; 2012b).
} 


\section{Introducción}

Los estudios de género son un movimiento surgido en los años setenta del siglo pasado que se dedica a la investigación de la identidad del género y a cómo esta es representada y percibida dentro de la sociedad. Centran su interés ante todo en el desequilibrio que prevalece entre los hombres y las mujeres, mostrando un interés especial por el aspecto del poder y con fenómenos a él vinculados como el abuso, el control y la dominación. Según OAKLEY (2000), el sexo se entiende como algo biológico, es decir, se determina mediante la identificación de la naturaleza de los genitales; por el contrario, el género es una construcción social. En otras palabras, se basa en la idea de que el género y los comportamientos con él conectados son un asunto principalmente sociológico y no biológico como se creía antes y, por tanto, que nuestra manera de actuar (masculina o femenina) se debe más al aprendizaje social que a la fisiología de nuestros cuerpos. Por otra parte, en todas las comunidades se crean estereotipos para hacer posible la comunicación; un estereotipo es una imagen global y generalizadora sobre un grupo social concreto basada en realidades incompletas (OAKLEY 2000). En relación al género, se trata de ideas generales de cómo debería ser un hombre y cómo debería ser una mujer ideales, es decir, cuáles son los atributos sociales de los que deberían disponer los respectivos géneros para cumplir con las expectativas de la sociedad. Así, DOYLE (1991) señala que hay cinco aspectos principales con los que suele vincularse el estereotipo del hombre: la anti feminidad, el éxito, la agresividad, la sexualidad y el control absoluto. De acuerdo a esto, los hombres no deberían semejarse a las mujeres y, por tanto, ocuparse de los asuntos que les son propios, como los trabajos del hogar o el cuidado de los hijos. Doyle relaciona el éxito con el hombre como ser activo y racional. En cuanto a la agresividad, esta se relacionaría con la competitividad que se considera típica de los hombres. Con "elemento sexual" Doyle se refiere a que los hombres son los iniciadores de las relaciones sexuales. Por último, mediante el control absoluto, los hombres no demuestran sus emociones que deben estar siempre bajo su dominio.

Por lo que se refiere al estereotipo de la mujer, DOYLE (1991) considera que la maternidad y el cuidado de los hijos se vinculan estrechamente con la identidad de las mujeres. Existen, por supuesto, otras características vinculadas con las mujeres, de modo que se espera que esta sea afectuosa, amable, gentil, empática y atenta a las necesidades de los demás (VALDROVÁ 2006). Por último, también hay que destacar el aspecto físico, es decir, si son atractivas, cómo se visten y cuál es su edad (GOÑI 2008).

La lingüística de género, por su parte, estudia cómo se reflejan los desequilibrios de género en los fenómenos gramaticales, además de cómo es el lenguaje de las mujeres y de los hombres, cuáles son sus respectivos rasgos y en qué aspectos se diferencian. Según HELLINGER (2002), las metáforas y los proverbios serían una parte de la lengua ideal para observar las jerarquías socio-culturales y la naturaleza de los diferentes estereotipos. HELLINGER (2002) propone varias muestras de conceptos que carecen de simetría en español; en cuanto al checo, destacamos aquí los trabajos de EISNER (1992) y VALDROVÁ (2004).

Nuestro trabajo parte, además, de los estudios de lingüística cognitiva sobre fra- 
seología, entre los que destacan los estudios sobre lenguaje figurado convencional (DOBROVOL'SKIJ 2005), a los que nos referiremos más adelante. Por otra parte, LAKOFF (1980) considera que, gracias al hecho de que entendemos el mundo, ante todo, mediante los sentidos, utilizamos construcciones metafóricas basadas en la experiencia corporal y espacial para expresar los aspectos más abstractos de nuestras vidas. Es decir, existen dos dominios: el dominio fuente, que es el experiencial, en cuyos términos entendemos el otro, más abstracto, que se denomina dominio meta. Para ilustrar cómo funciona el concepto podemos utilizar el ejemplo de la metáfora "tiempo es dinero", donde el concepto del dinero se conceptualiza mediante el concepto del tiempo y, así, se crean expresiones como: ganar tiempo, malgastar el tiempo, ahorrar tiempo, etc. (cfr. SORIANO 2012).

Si nos centramos ahora en las metáforas relativas a los animales, resulta necesario hablar del concepto Great Chain of Being Metaphor ('Metáfora de la gran cadena de los seres'), desarrollado por LAKOFF (1989). Esta teoría se basa en la tendencia humana a percibir el mundo que nos rodea como jerarquizado. Así, existe un modelo cultural que ubica a diferentes tipos de seres y objetos en una escala vertical, ordenados según sus características y haciendo, de esta manera, a ciertos seres inferiores respecto a otros. En el lugar más alto de la escala podemos encontrar el concepto del ser humano (aunque en algunas variaciones culturales también puede hallarse el concepto de Dios o de Cosmos). El hombre dispone de características como es el razonamiento, el sentido estético, la moralidad, la comunicación o la consciencia. Por debajo del hombre se ubican los animales, cuya característica más saliente es el comportamiento instintivo. Debajo de los animales encontramos las plantas, cuyas funciones son, ante todo, las biológicas. Finalmente, en la parte más baja de la escala se hallan los objetos inanimados caracterizados por sus cualidades materiales. Lakoff y Turner creen que este modelo, a pesar de ser inconsciente para la mayoría de las personas, está generalizado y resulta crucial para nuestro entendimiento y conceptualización del mundo. Gracias a la teoría de la Metáfora de la gran cadena de los seres, según los autores, podemos entender a unos seres en términos de otros y así, también, aparte de otros fines, expresar la superioridad de unos ante otros y al revés.

Considerando los objetivos de este trabajo, es útil mencionar que LAKOFF (1989) amplió la teoría de la Metáfora de la gran cadena a ciertos subniveles. De esta manera existen animales como leones, osos y otros carnívoros que tienen superioridad sobre otros, como las gacelas, los ciervos o las serpientes. Del mismo modo, también puede observarse que, dentro del nivel del ser humano, los hombres tienen superioridad sobre las mujeres. Estas apreciaciones, junto con la aclaración de los autores de que no solo se trata de una jerarquización y una adscripción de diferentes propiedades a ciertos seres, sino que también se trata de una manera de expresar la relación de dominación y subordinación, nos son muy útiles para la presente investigación.

Además, en LAKOFF (1989) se pone en cuestión la convicción general de que las metáforas relativas a animales se basan en una simple similitud entre dos dominios. Los autores están convencidos de que, al emplear una metáfora de este tipo, surge un mecanismo mucho más complejo. Para explicar cómo funciona, presentan 
el ejemplo de la metáfora Aquiles es un león. A primera vista, puede parecernos que se trata de un simple parecido (la valentía) entre los dos dominios: Aquiles y león. Sin embargo, lo que se nos escapa al proponer esta conclusión es que la valentía realmente no es un rasgo instintivo típico de los animales, sino una característica considerada puramente humana en cuyos términos ya se había entendido el comportamiento instintivo de los leones antes del surgimiento de la metáfora. Es decir, no es trata de un parecido, sino que estamos ante la aparición de dos metáforas contradictorias, de las que una implica que los leones disponen de valentía como los hombres y la segunda vuelve a entender a un hombre en términos del animal al que ya se le había adjudicado dicha propiedad humana. Entonces, ¿cuál es la diferencia entre decir Aquiles es valiente y Aquiles es un león? Lakoff y Turner afirman que de lo que se trata realmente es de expresar la relación que hay entre la propiedad y su propietario. Ya sabemos que según la teoría de la Metáfora de la gran cadena lo típico de los animales es su instinto y el instinto animal es algo muy exacto. Entonces, cuando entendemos a Aquiles en términos del león lo que de verdad queremos destacar, sobre todo, es la solidez de la valentía de Aquiles. En la terminología de Dobrovol'skij y Piirainen posiblemente se podría tratar del valor semántico adicional de la metáfora (DOBROVOL'SKIJ 2005).

Por otra parte, DOBROVOL'SKIJ (2005) afirma que la cultura tiene su propia memoria colectiva gracias a lo que es posible que diferentes conceptos se enraícen en diferentes culturas de una forma, a veces, sorprendentemente distinta. El hecho de que el lince, por ejemplo, esté presente en la fraseología de muchos idiomas -con frecuencia asociado con la buena vista-, a pesar de estar ya extinguido en la mayoría de los países, unido a que, desde el punto de vista biológico, son animales que no disponen de buena vista, significaría que su aparición y representación son motivadas por un conocimiento simbólico compartido. Por su parte, LUQUE NADAL (2012: 68) afirma que los fraseologismos de animales o zoologismos "se basan en ciertos aspectos de la anatomía y la conducta de los animales que pueden interpretarse como signos de fenómenos emocionales en estos animales", es decir, cuando observamos a un animal, lo que hacemos es proyectar en él características humanas. Esto, naturalmente, significa que "centenares de fraseologismos reflejan la conducta animal, vista siempre desde la perspectiva humana, lo que determina que la visión sea, a veces, muy subjetiva".

\section{Principios metodológicos}

El objetivo de la investigación es analizar el reflejo de los modelos sociales de género en los zoologismos checos y españoles. Se han recogido unidades fraseológicas de dos fuentes, una española y otra checa, y se ha creado un corpus cuya parte española conste de 61 unidades fraseológicas y la checa de 210; de estas hemos ido eligiendo, según diferentes criterios, unidades concretas para el análisis. De lo expuesto aquí salta a la vista el importante desequilibrio en el número de unidades

\footnotetext{
2 Zoologismo sería "el uso metafórico o alegórico de un animal para referirse a una conducta o una característica del hombre en el acervo fraseológico" (KEKIĆ 2008: 107-108).
} 
fraseológicas en ambas lenguas causado, en parte, por habernos servido de dos tipos de fuentes distintas: un diccionario fraseológico general para el español, concretamente SECO (2006), y un trabajo específico sobre zoologismos para el checo, MRHAČOVÁ (1999). Reconocemos que esta disparidad puede tener un efecto negativo sobre el análisis comparativo español-checo, para lo que habría sido, sin duda, más adecuado emplear asimismo un diccionario fraseológico general para el checo (ČERMÁK 2009). Sin embargo, hemos decidido emplear el trabajo de Mrhačová dado que este incluía un número muy elevado de zoologismos y puesto que en este trabajo no pretendemos llevar a cabo tanto una comparación cuantitativa como cualitativa. Por otra parte, dado que el trabajo de SECO (2006) se refiere exclusivamente a unidades fraseológicas del español peninsular -y dada la enorme variedad dialectal de la lengua española-, todos los datos y conclusiones presentados a lo largo de este trabajo se referirán exclusivamente a esta variante del español.

Antes de seguir, consideramos adecuado subrayar que, en lo que se refiere a la terminología, para nuestro análisis hemos utilizado el término general unidad fraseológica (UF) para abarcar todos los elementos objeto de estudio. Seguimos así las terminología empleada en varios trabajos actuales en español que abordan el estudio de la fraseología, como nosotros, desde la perspectiva cognitiva (cfr. TIMOFEEVA 2012) y que continúan con la tradición terminológica instaurada en la fraseología española por CORPAS PASTOR (1996) con la que pretendía terminar con la enorme falta de coherencia al respecto.

Para llevar a cabo una investigación de este tipo, es importante que seamos capaces de representar de una manera cualitativa la naturaleza de las metáforas contenidas en cada una de las unidades del modo que sea más objetivo posible. Esto, sin embargo, no es una tarea fácil. Ya LAKOFF (1980) demuestra que, cuando empleamos las metáforas, ocurre que algunos aspectos de los conceptos se hacen más visibles mientras otros aspectos se hacen menos visibles o hasta invisibles. Para estudiar con más facilidad y sistematicidad los estereotipos y llevar así a cabo su investigación, GUTIÉRREZ RUBIO (2013a; 2013b) ha utilizado un concepto denominado estereotipo conceptual focalizado (conceptual stereotype in focus) ${ }^{3}$ mediante el que tratar de captar cuál es el rasgo más saliente la unidad estudiada. Así, el autor afirma que "una unidad fraseológica no refleja todos los conocimientos o estereotipos que comparte (buena parte de) una sociedad sobre un elemento concreto" (GUTIÉRREZ RUBIO 2013a: 123). El estereotipo conceptual focalizado (ECF) es, según él, el aspecto más saliente del concepto, que se activa en nuestra mente al emplear una metáfora concreta. Por ejemplo, el ECF de la unidad hablar en chino sería la incompresibilidad o el de la unidad hecho una bestia se definiría como la fuerza física.

Como punto de partida para establecer el análisis hemos elegido la naturaleza de los dominios meta y fuente y la naturaleza de su hipotética relación. En otras palabras, intentamos prever cuáles podrían ser los ECF concretos representados por diferentes tipos de unidades y de qué género podrían ser los animales que representan los dominios meta y fuente. Basándonos en KIMMEL (2011), en cuanto a la representación de los roles sociales, y en DOBROVOL'SKIJ (2005), según el que cada

3 En estas publicaciones este mismo concepto aparece aún bajo la denominación foco cognitivo. 
unidad tiene una estructura semántica que es importante que se conserve para que su sentido sea comprensible para los hablantes, elaboramos cuatro hipótesis principales. Según la primera hipótesis suponemos que, en cuanto a las unidades cuyo dominio fuente se representa por un animal macho y cuyo dominio fuente es de género masculino, es decir, "los hombres son animales macho", los ECF podrían representar las características normalmente relacionadas con los hombres, como es la agresividad, la fuerza, la dominancia, la competitividad, la tozudez o la valentía. En cuanto a la metáfora "las mujeres son animales hembra" creíamos que podría tratarse de características generalmente percibidas como femeninas como son, por ejemplo, el afecto, la alegría, la compasión, la timidez o la pasividad, o bien relacionadas con la apariencia física y, especialmente, la fealdad y la belleza. Por lo que se refiere a las metáforas cuyos dominios meta y fuente son de diferentes géneros, creemos que podría tratarse de unidades que hacen referencia a situaciones en las que la manera de actuar de los referentes no corresponde a sus roles sociales de género. Por ejemplo, en cuanto a la metáfora "las mujeres son animales macho", consideramos posible la aparición de características como la fuerza, la valentía, la dominación o la tozudez; una mujer representada por un animal macho también podría ser una mujer temperamental y difícil de controlar. Por último, creemos que mediante la metáfora "los hombres son animales hembra" los hablantes podrían referirse a un hombre débil, cobarde, sumiso o afeminado.

Somos conscientes del hecho de que hay metáforas que pueden referirse tanto a un hombre como a una mujer. En estas situaciones hemos accedido a observar los ejemplos del uso real que se incluyen en los diccionarios y el razonamiento común de hablantes nativos, siempre teniendo en mente las ya mencionadas afirmaciones de DOBROVOL'SKIJ (2005) que dice que, cuando usamos una unidad de una manera incorrecta, o le añadimos ironía o humor, violamos su estructura semántica y la hacemos, así, incomprensible, que es lo que queremos evitar (si no fuera por esta manera de restringir, tendríamos que analizar hasta el infinito todas las unidades en todas las posibles combinaciones).

\section{Análisis}

\subsection{Estereotipos más frecuentes según el género}

En primer lugar, presentamos en la tabla 1 los ECF asociados a los animales de género masculino extraídos de las unidades fraseológicas de nuestro corpus, ordenados según la frecuencia de su aparición:

Tabla 1. ECF asociados a los animales de género masculino

\begin{tabular}{|c|c|}
\hline $\begin{array}{l}\text { Checo } \\
\text { agresivo (12), grande, fuerte (9), asqueroso, dormilón, de } \\
\text { colores (rojo, negro) (7), estúpido, perezoso, rápido (6), } \\
\text { testarudo, buena vista, hambriento (5), ágil, canta bien, } \\
\text { lento, trabajador (4), orgulloso, astuto, asustado, débil, } \\
\text { inteligente, obediente, problema, ruidoso, solitario, taca- } \\
\text { ño (3), potente, maloliente, despeinado, enamorado, } \\
\text { gordo, llorón, peligroso, pequeño, pesado, sano, torpe } \\
\text { (2), impotente, borracho, engañoso, sucio, sagaz, moja- } \\
\text { do, rizado, sano, delgado, extravagante (1) }\end{array}$ & $\begin{array}{l}\text { Español } \\
\text { rápido (8), agresivo, fuerte, sucio (4), furioso, pequeño, } \\
\text { insignificante (3), dañino, arrogante, astuto, dormilón, } \\
\text { feroz, intensidad, peligroso, raro, salvaje ( } 2 \text { ), torpe, ágil, } \\
\text { bruto, buena vista, testarudo, culpable, fácil de engañar, } \\
\text { feo, grande, grosero, homosexual, afeminado, loco, } \\
\text { orgulloso, perezoso, pesado, poca vista, potente, trabaja- } \\
\text { dor, valiente (1) }\end{array}$ \\
\hline
\end{tabular}


Por lo que se refiere a los estereotipos relacionados con los animales que tienen género femenino, estos se exponen por orden de frecuencia en:

\section{Tabla 2. ECF asociados a los animales de género femenino}

\begin{tabular}{|c|c|}
\hline $\begin{array}{l}\text { Checo } \\
\text { estúpida, ágil (10), delgada (9), agresiva, rápida (6), } \\
\text { habladora, trabajadora, maliciosa, vivaz, pesada, sumisa, } \\
\text { pasiva (5), trasero grande, torpe, inteligente, gorda, } \\
\text { pequeña, ligera, verde, pálida (3), sana, furiosa, astuta, } \\
\text { callada, parásito, grosera (2), obediente, muda, sorda, de } \\
\text { dudoso moral, descuidada, tímida, grande, tranquila, } \\
\text { atractiva, cobarde, acechadora, fuerte, lenta (1) }\end{array}$ & $\begin{array}{l}\text { Español } \\
\text { loca, pesada (3), apresada, agresiva, bajo/fuera de co } \\
\text { trol, cintura delgada, feroz, frívola, fuerte, gorda, habl } \\
\text { dora, pesada, trabajadora (2), grande, furiosa, ágil, ast } \\
\text { ta, cobarde, cruel, demasiado fértil, desconfianza, fe } \\
\text { grosera, insignificante, irritante, pene, repulsiva, suc } \\
\text { valiente (1) }\end{array}$ \\
\hline
\end{tabular}

A primera vista podemos observar que las características relacionadas con los animales de género masculino como la agresividad, el gran tamaño o la fuerza se corresponden bastante con los estereotipos que habíamos indicado con antelación. En cuanto a los rasgos femeninos, encontramos la locura o la estupidez que, en comparación con las masculinas, son unas características bastante negativas. Esto puede deberse al hecho de que, mediante la fraseología relativa a animales, muchas veces lo que quiere destacarse es un rasgo negativo, porque se compara con animales que son, según la teoría de la Metáfora de la gran cadena, inferiores a los hombres (LAKOFF 1989). En lo que se refiere a otros rasgos percibidos como femeninos, también se trata, muchas veces, de palabras que se relacionan con características físicas de las mujeres como es la delgadez y la agilidad (positivamente valoradas) o la gordura (negativamente valorada).

Para investigar de una manera más profunda cómo surgieron estas alusiones podemos fijarnos en el hecho de que en las tablas 1 y 2 hay principalmente dos tipos de características. Por una parte, observamos adjetivos que suelen designar comportamientos que pueden asociarse tanto con seres humano como con animales (agresivo/a, rápido/a, fuerte, asqueroso/a o peligroso/a); por otra, adjetivos que denominan comportamientos claramente humanos (estúpido/a, orgulloso/a, arrogante, testarudo/a, borracho, astuto/a, trabajador/a, tacaño/a, valiente, enamorado, callada, grosera o tímida).

Aunque son importantes para el análisis todas las características, ya que siempre tratamos de expresar un rasgo saliente que, al final, acaba proyectándose en un ser humano (ya que la metáfora final siempre acaba siendo "las personas son animales"), y así resaltan cuáles son las necesidades expresivas más frecuentes de los hablantes, el segundo grupo es mucho más interesante para nosotros. Para saber por qué, es conveniente recordar, una vez más, las ideas de LAKOFF (1989) sobre el surgimiento de las metáforas relativas a animales, según las que surgen dos metáforas al mismo tiempo. En cuanto a las características del segundo grupo, es decir, claramente humanas, esta teoría se ha comprobado, ya que es fácil observar que la alusión surgió primero en los humanos, es decir, las características humanas se proyectaron primero a los animales y solo después se volvieron a proyectar estos rasgos a los humanos.

Si observamos ahora estos resultados bajo los criterios de los estudios de género -que indican que tanto en la sociedad como en el lenguaje prevalece un desequili- 
brio entre los hombres y las mujeres (VALDROVÁ 2006)- combinándolos con la teoría de la Metáfora de la gran cadena de LAKOFF (1989) -que las metáforas de animales añaden un valor semántico a la relación entre el dominio meta y fuente ya que esta se vincula con el instinto animal-, podríamos afirmar que es posible que muchas de las unidades fraseológicas investigadas hayan sido creadas y utilizadas para justificar ciertos comportamientos humanos como la agresividad de los hombres o la estupidez de las mujeres, porque gracias a estas unidades han podido ser asimiladas por los miembros de las sociedades como fenómenos naturales.

\section{2. "Las mujeres son animales"}

A continuación nos centramos en algunas de las unidades fraseológicas que contienen la metáfora "las mujeres son animales". Concretamente hemos analizado 55 unidades de las que 45 están en checo y las restantes 10 unidades son españolas.

\subsubsection{Características fisicas de la mujer}

Por lo que se refiere a las unidades fraseológicas que tienen como referente a una mujer, tanto en checo como en español, son bastante numerosas las que hacen alusiones al aspecto físico. Estas unidades, sobre todo, valoran el aspecto de una manera negativa o positiva, dan recomendaciones acerca de cómo debería ser el aspecto físico de las mujeres en general, contienen comentarios sobre la delgadez, la agilidad (rasgos generalmente positivamente percibidos por los hablantes) o la gordura de las mujeres (que es negativamente percibida). En los corpus hemos encontrado varias unidades que, de alguna manera, hacen referencia al físico de las mujeres y las hemos analizado con más detalle.

En cuanto a las que cabría evaluar como positivas en checo, hemos documentado las siguientes: (1) To je ale kočka!; (2) To je (ale) roztomilá žabka!; (3) To je ale koroptvička!; (4) být štíhlá jako lan̆; (5) nosit se/ nést se jako lan̆; (6) mit nohy/ nožky jako laňka; (7) mít nohy jako srnka; (8) (být) štíhlá jako gazela; (9) mít nožky jako gazela; (10) hadí žena; (11) mít pas jako vosa; (12) mit oči jako laň; (13) mit šíjil krk jako labut'/ labut'i šíji. En español hemos encontrado solo una UF que hace una referencia directa al aspecto de la mujer con connotación positiva: (14) cintura de avispa. Entre las negativas se incluirían: (15) como una foca; (16) como una vaca.

Las unidades (1), (2) y (3) valoran el aspecto físico en general, la primera, que hace referencia al atractivo de la mujer, podría traducirse como ‘ $i$ Menuda gata!'; la segunda (2) se refiere a una chica o a una niña más joven y se refiere a su monería o gentileza mediante una metáfora cuyo dominio fuente es rana en su forma diminutiva ( $\check{a} a b k a)$; la tercera (3) describe a una mujer joven y guapa mediante el dominio fuente perdiz (koroptvička). Luego, hay muchas unidades que hacen alusiones a la delgadez; en las unidades (4), (5), (6) y (7) se hace una comparación de las piernas de una mujer con piernas de una corza (srna), una cierva (lan̆) y una gacela (gazela), dando importancia al hecho de que es conveniente que una mujer tenga unas piernas delgadas y largas. En la unidad checa (11) y en la unidad española (14) también se trata de la delgadez pero se hace referencia a otra parte del cuerpo de la mujer: la cintura. La unidad (10) 'mujer serpiente' destaca la flexibilidad (probablemente sin 
carga positiva ni negativa) y la unidad (7), que se refiere a una corza, la agilidad. La unidad (12) compara los ojos de una mujer con los ojos de una cierva; la cierva en checo se considera un animal frágil y la impresión que evoca es que necesita protección. Por lo que se refiere a la unidad (13), que describe un cuello delgado mediante la comparación con el cuello de un cisne (labut'), el diccionario no señala explícitamente que solo se pueda referir a una mujer. Aun así consideramos poco probable que alguien la utilice en relación con un hombre.

En cuanto a las unidades que describen el aspecto físico de la mujer como rasgo percibido por los hablantes de un modo más bien negativo, destacan sobre todo la gordura, relacionada con las frases españolas (15) y (16), que tienen como dominios fuente dos animales de género femenino: la vaca y la foca.

Creemos que en checo esta semántica se expresaría, por ejemplo, mediante el símil jako prase, es decir, 'como un cerdo/a', que, sin embargo, puede referirse a ambos géneros y no solo a las mujeres. A pesar de esto, en checo también hemos encontrado frases que se refieren a la gordura (o al tamaño grande en el sentido físico) de la mujer: (17) mit zadek jako klisna; (18) mit zadek jako kobyla; (19) To je ale klisna/ klisnička!

Estas frases contienen las palabras kobyla y klisna ('yegua') con lo que las unidades (17) y (18) se refieren concretamente al trasero de una persona y, aunque el diccionario no lo señale explícitamente, los ejemplos del uso real siempre indican que se habla de una mujer. La última unidad (19) hace referencia a una mujer robusta pero, probablemente a causa de que el dominio fuente se exprese a través de una forma de diminutivo, también se alude a la belleza. En el caso de estas unidades es más difícil decir cómo se perciben realmente por los hablantes las características que describen. En el entorno socio-cultural checo el trasero de una mujer puede valorarse tanto positiva como negativamente.

Para cerrar esta sección, resulta necesario comentar aún varias unidades que hacen alusiones al aspecto físico de las mujeres: (20) být naličená jako ochechule; (21) vypadat jako ochechule; (22) como una mona / más que una mona.

La traducción literal de las unidades (20) y (21) sería 'estar maquillada como un manatí' y 'ser como un manatí'; su propósito es denotar que una mujer se ha maquillado demasiado. Gracias a estas unidades podemos observar que, a veces, la alusión que se crea mediante algunas unidades tiene poco que ver con la verdadera naturaleza de sus dominios fuente. Creemos que la mayoría de los hablantes checos desconocen por completo el aspecto de un manatí (un mamífero marino de color blanco $)^{4}$. El equivalente español para estas frases sería la unidad (22) con el dominio fuente mona. Este dominio fuente femenino es, sin embargo, poco utilizado en otros contextos.

\subsubsection{Mujer en las frases con connotación sexual}

Tanto en checo como en español podemos encontrar unidades que se refieren al comportamiento sexual de las mujeres. Estas unidades, en muchos casos, tienen

\footnotetext{
4 Consideramos posible el hecho de que el origen de esta unidad se halle en la mitología antigua relacionada con el hecho de que los marineros vinculaban los manatís con las sirenas; esto, sin embargo, la mayoría de los hablantes checos probablemente no lo sepa.
} 
como propósito valorar el nivel moral de las mujeres. Se refieren, a menudo, a su frivolidad o dudosa moral y las valoran negativamente: (23) Čubka jedna (zatracená)!/ To je ale čubka!; (24) Když čubka nechce, pes neskočí.

Así, las unidades (23) y (24) que contienen la palabra čubka (perra) hacen referencia a mujeres cuyo moral, según MRHAČOVÁ (1999), puede considerarse dudosa. La unidad (23) es un insulto fuerte que se refiere a una mujer antipática, frívola y malvada. La unidad (24) es un proverbio cuya traducción podría ser 'cuando la perra no quiere, el perro no la monta'. Aquí podemos ver que una situación de dos perros que se aparean se aplica a una situación de dos personas que tienen relaciones sexuales. El significado del proverbio indica que solo puede accederse al coito cuando la mujer acepta; sin embargo, mirando la intención de la unidad con más detalle, y desde el punto de vista de los estudios de género (GOÑI, 2008), podemos deducir que es posible emplearla como justificación del comportamiento de un hombre que está forzando a una mujer a tener sexo con él.

En español también hemos encontrado unidades que tienen como dominio meta a una mujer a la que se le adjudica, según el diccionario de SECO (2006), la característica de frivolidad: (25) cabra loca; (26) pájara pinta; (27) más puta que las gallinas. La UF (25), aparte de frivolidad, también indica locura, ya que la contiene explícitamente. En (26) se define a la referente como a "una mujer de moral sexual relajada" (SECO 2006: 720). En este caso podemos observar que, además, la UF contiene una forma léxica inusual de la palabra pájaro con el sufijo femenino - $a$ que hace resaltar la alusión al comportamiento inadecuado de la mujer. La unidad fraseológica (27), según el diccionario, describe a una mujer frívola que goza de una excesiva libertad, es decir, que tiene "costumbres libertinas" (SECO 2006: 485). Esta unidad indica implícitamente el estereotipo de que la libertad (sexual) de la mujer debería limitarse.

\subsubsection{Mujer y su edad}

Aparte de las frases que hacen una alusión directa a la frivolidad o sexualidad de las mujeres, también pueden encontrarse unidades que se refieren a la edad de sus referentes y a los aspectos que suelen vincularse con ella: (28) je to ještě pulec; (29) lepši se uhlídá pytel blech než mladé děvče; (30) como vaca sin cencerro. La UF (28) compara a una chica joven con un renacuajo (pulec) haciendo resaltar su poca experiencia en la vida (o con frecuencia también en el sexo). El propósito de la unidad (29) es parecido pero, además, se añade la alusión a las dificultades que hay con el control de las chicas jóvenes, indicando, otra vez, que su libertad debería limitarse. La UF española (30), por el contrario, tiene como dominio meta a una mujer mayor y no casada, llamando la atención sobre el hecho de que su situación es inconveniente y la describe como "sin rumbo" (SECO 2006: 1010).

\subsubsection{Mujer como madre}

El rol de la mujer como madre es un concepto importante en cuanto a su papel en la sociedad (VALDROVÁ 2006). Por eso no es sorprendente que en ambos idiomas puedan encontrarse unidades que tienen como dominio meta una mujer que ocupa esta función: (31) krkavči matka; (32) kráva už zapomněla, že byla teletem; 
(33) como una coneja. La unidad checa (31) es peyorativa y hace referencia a la característica de codicia en una madre comparándola con un cuervo (krkavec), representado por un dominio fuente masculino que hace resaltar su comportamiento inadecuado; mientras, la unidad (32) 'la vaca ya ha olvidado que una vez fue ternero', mediante un domino fuente femenino, hace referencia a una situación en la que la madre no tiene suficiente comprensión para los asuntos de sus hijos. La UF española (33) representa a la mujer como una madre excesivamente fecunda, comparándola con una coneja, que es un animal conocido por su fertilidad, esta unidad también puede considerarse peyorativa.

\subsubsection{Mujer trabajadora}

Dentro de las unidades fraseológicas que hemos recogido también aparece frecuentemente el elemento del trabajo. Entre las numerosas frases relacionadas con este tema se han encontrado las siguientes que contienen una alusión directa a la metáfora "las mujeres son animales": (34) To je ale pilná včelička!; (35) To je ale čečetka! La unidad (34) hace alusión a la diligencia de una mujer mediante una metáfora cuyo dominio fuente es de género femenino y tiene forma diminutiva: una abejita (včelička); la abeja es un insecto conocido por su actividad laboral. Por lo que se refiere al dominio fuente de la metáfora (35), se trata de un tipo de pájaro, el pardillo (en latín Acanthis). Podría afirmarse que estas dos UF valoran la actividad laboriosa de las mujeres de una manera bastante positiva.

\subsubsection{Otras características}

No es sorprendente que en las unidades relativas a animales aparezca frecuentemente como ECF la agresividad. Por lo que se refiere a unidades que tengan como referente a una mujer, normalmente suelen utilizarse unidades que pueden tener como dominios meta a un referente de ambos géneros, empleadas, en la práctica, mediante la metáfora "las mujeres son animales macho" como, por ejemplo, být rozzuřená jako býk, o sea, 'estar furiosa como un toro'. En cuanto a unidades con alusión directa a la mujer, estas tienden a destacar, aparte de la agresividad en sí, también la rabia o el peligro que suponen, es decir, se representa a las mujeres como seres agresivos, furiosos y difíciles de controlar: (36) ta ženská je hotová/ učiněná saň; (37) štěkat na někoho jako fena; (38) rvát se jako feny; (39) Ty jsi (ale) (hotovál učinèná) tygřice!

En la unidad (36) podemos observar que el dominio fuente es la dragona (san̆), un animal mítico conocido por su fuerza y peligrosidad. El dominio fuente de las unidades (37) y (38) es la perra (fena). Mediante estas dos unidades se subraya la agresividad de las referentes y el peligro que suponen, pero además se las muestra como inferiores. En la unidad (39), cuyo dominio fuente es una tigresa (tygřice), la hembra de un felino peligroso, se hace referencia no solo a la agresividad, al temperamento (y, a veces, a la valentía) de su referente, sino también, en algunos contextos, podemos notar una connotación sexual con carga positiva.

Aún dentro de la metáfora "las mujeres son animales" destaca otro ECF: la astucia. Esto lo observamos en la UF española (40), con el dominio fuente zorra: (40) como una zorra. Por lo que se refiere a los zorros, en las dos sociedades, checa y 
española, generalmente se considera que son animales inteligentes y astutos; sin embargo, en el entorno socio-cultural español también es muy conocida la denominación zorra para llamar frívola o prostituta a una mujer. Esto, sin embargo, el diccionario de Seco no lo señala.

Además, los resultados del análisis han indicado que en checo puede hallarse un número alto de unidades que se utilizan para llamar estúpida a una mujer, todas estas UF, en el diccionario, están tratadas como insultos: (41) Ta ovce jedna hloupá! / To je ale ovce pitomá!; (42) Ta kráva jedna blbá! / To je ale kráva pitomá!; (43) Husa jedna pitomá!/ To je ale husa hloupá!; (44) Káčo jedna pitomá!/ Ty jsi ale káča!; (45) Slepice jedna pitomá!/ To je ale slepice!; (46) Koza jedna (stará) (pitomá)!/ Ty jsi (ale) koza (nebeská)!; (47) Ta krůta jedna (stará)/ To je ale krůta. Estas unidades fraseológicas utilizan como dominio fuente denominaciones de animales hembras como oveja (41), vaca (42), oca (43), pata (44), gallina (45), cabra (46) y pava (47). Aparte del propósito de destacar la estupidez de las referentes, también se hace referencia a otras cualidades consideradas negativas por los hablantes, como la indiferencia, la ignorancia, el orgullo, la ingenuidad (43), la torpeza (44), la excesiva religiosidad (46) o la vejez (47).

Otra característica tratada con una frecuencia considerable en las unidades checas es la timidez de la mujer: (48) být plachá jako laň; (49) být plachá jako srna; (50) (být) plachá jako gazela. Estas UF tienen como dominio fuente a animales ya mencionados más arriba con relación a la delgadez: cierva (48), corza (49) y gacela (50). Mediante las unidades que tienen como estereotipo focalizado la timidez se expresa la fragilidad de las mujeres y, probablemente, también el hecho de que necesitan ser protegidas.

Por último, nos gustaría introducir algunas unidades checas con la metáfora "las mujeres son animales" cuyo propósito es comentar otras características negativas de las mujeres. Las frases son negativas en su totalidad, es decir, tanto en el nivel de la percepción de los hablantes en la sociedad como desde el punto de vista de los estudios de género. Todas ellas son insultos: (51) Sưva jedna (stará)/ To je ale sưva!; (52) Škeble jedna (stará)!; (53) Můra jedna (stará) (zatracená)!/ To je ale stará můra; (54) Źába jedna drzá!/ To je ale drzá žába; (55) zmije jedna (falešná) (proradná). Las unidades que utilizan como dominio fuente las palabras búho (sưva) (51), almeja (52) y polilla (53) hacen, a la vez, referencia a la vejez y antipatía de las mujeres. La frase (54) tiene como estereotipo focalizado el descaro y su dominio meta es la rana (žába), probablemente a causa de la boca grande que estas tienen. La última UF (55) con el dominio fuente víbora (zmije) representa a la mujer como ser falso. En todas estas unidades observamos que todos los dominios fuente, sin excepción, tienen género femenino.

\section{3. "Los hombres son animales"}

Debemos comenzar señalando que la mayoría de los animales que aparecen en las unidades recogidas en los corpus tienen género masculino, es decir, en la fraseología relativa a animales prevalece el elemento masculino en cuanto a los dominios fuente. Sin embargo, a la hora de la búsqueda de frases concretas que contengan la metáfora directa "los hombres son animales" observamos que son más escasas que 
las metáforas "las mujeres son animales". Este hecho puede deberse al fenómeno de la parcialidad del género (el masculino es el género no marcado, de modo que cuando se dice niños también se incluye a las niñas en el enunciado, pero no al revés). Creemos que este fenómeno podría haberse reflejado también en la manera de describir las UF en los diccionarios (con frecuencia se señala explícitamente cuándo una unidad solo puede referirse a una mujer; mientras que, en el caso del hombre, no queda tan claro si la mujer se incluye en el significado o no).

Como ya se ha dicho, las unidades con la naturaleza concreta "los hombres son animales", es decir, las unidades que tienen como referente exclusivamente a un hombre, no son muy numerosas. Sean cuales sean las razones para esto, en esta parte del análisis hemos decidido acceder a la investigación solamente de las unidades cuyas descripciones en los diccionarios señalen explícitamente que se refieren exclusivamente a hombres, para evitar llegar a conclusiones poco claras o equívocas. Así, hemos analizado 30 unidades, 16 de ellas checas y 14 españolas.

\subsubsection{Hombre con connotación sexual}

La connotación sexual es la característica más frecuente en las unidades que tienen como dominio meta exclusivamente a hombres. Muchas de ellas tienen como propósito no solo destacar la fertilidad, la potencia y la frecuente actividad sexual de los hombres, sino también valorarla positivamente. Pensamos que en este punto es conveniente volver a recordar que se trata de unas características que son consideradas instintivas y, por tanto, el empleo de las unidades fraseológicas que las contienen puede, en algunas situaciones, tener como propósito justificar ciertos comportamientos (como la violencia o la promiscuidad). Además, como ya se ha dicho en comparación con las unidades con la misma connotación que tienen como dominio meta a una mujer, las que lo contienen en la forma masculina suelen ser unidades que describen acciones que no son tan negativamente percibidas por los hablantes: (1) To je ale bejk; (2) To je ale kanec!; (3) To je ale hřebec!; (4) dobrý kohout neztloustne; (5) salto de tigre; (6) ponerse burro (un hombre)/ poner burro (a un hombre); (7) irsele las cabras. En la UF (1) se compara al hombre con un toro (býk), en la (2) se trata de un jabalí (kanec) y en la (3) aparece el caballo semental (hřebec); todas ellas hacen alusión a la buena potencia sexual y puede decirse que las tres son percibidas de una manera positiva por la sociedad, es decir, suelen utilizarse para alabar el comportamiento sexual de los hombres. Igualmente, en la unidad checa (4), cuya traducción podría ser 'un buen gallo no engorda', observamos la alusión a un animal macho, el gallo (kohout), al que se hace referencia (positiva) por tener una buena forma física causada por una alta actividad sexual. La unidad fraseológica española (5), que tiene como dominio fuente a un tigre y cuya descripción según el diccionario de Seco es: "acometida violenta del hombre sobre la mujer para realizar el acto sexual" (SECO 2006: 907), añade además a la connotación sexual la alusión a la violencia, si bien en este caso la relación sexual se entiende como consentida por parte de la mujer. La frase (6), con el dominio fuente burro, designa la excitación sexual. La última frase (7) española utiliza un dominio fuente femenino, pero no se refiere directamente a un hombre, sino que utiliza una situación cuando no se tiene control (cuando al pastor se le escapan las cabras); en comparación con las demás, designa 
una situación desagradable, generalmente negativamente percibida y se refiere a una eyaculación precoz. En este caso, lo que observamos es un dominio fuente femenino y una unidad que tiene como propósito ridiculizar un hombre en una situación poco favorable desde el punto de vista de los hablantes.

En cuanto a las unidades checas, entre las frases con connotación sexual también pueden encontrarse unidades que hacen referencia a la edad de los hombres. Se trata de hombres de edad avanzada que tienen interés por mujeres jóvenes: (8) Ty jeden (starý) (mlsný) kocoure!/ To je ale starý mlsný kocour; (9) Ten starý kozel!/ Kozel jeden (starý, opelichaný)! En la frase (8) el dominio fuente es un viejo gato con la característica de goloso (starý mlsný kocour) y en la (9) se trata de un macho cabrío mayor (starý kozel), en ninguna de las dos puede decirse que tengan una carga negativa, sino que más bien se trata de alusiones positivas (con la excepción de la segunda variante de (9) que hace alusión al asco). Aparte de UF que tratan la edad avanzada de los hombres, también pueden hallarse unidades que se refieren a su juventud: (10) edad del pavo; (11) být úplný bažant. En la unidad (10), cuya definición en el diccionario de Seco es "edad de la adolescencia, en que los muchachos muestran carácter difícil e inestable" (SECO 2006: 412), se refiere a un hombre joven mediante el dominio fuente pavo; es un hombre joven y sin experiencia. En checo hemos encontrado la frase (11) que puede considerarse sinónima a (10) pero donde el ave mediante el que se hace la referencia es el faisán (bažant). En lo que se refiere a estas dos UF, hay que añadir que, por lo menos la variante española (aunque el diccionario de Seco no lo señale), puede igualmente utilizarse con un dominio meta femenino; en el caso de la variante checa, el empleo de un dominio meta femenino quizás sea posible, pero no muy común.

Otro tema frecuentemente tratado por las unidades que tienen como dominio fuente a un hombre es el de un hombre mujeriego que cambia frecuentemente de pareja: (12) (být) přelétavý jako motýl; (13) (být) přelétavý jako pták; (14) periquito entre ellas. En checo hay dos unidades fraseológicas que hacen referencia a un hombre promiscuo; la (12) lo hace mediante el dominio fuente mariposa (motýl) que se conoce por ir de flor en flor; se trata de un insecto de colores, es decir, bonito, de modo que a un hombre al que se hace alusión mediante este dominio fuente se lo considera atractivo o hasta vanidoso. La unidad (13) realiza la comparación de un hombre con un pájaro, que se considera, al igual que en el caso de la mariposa, un ser inestable en cuanto a su posición porque vuela de un sitio a otro. Asimismo la frase española (14) hace referencia a un pájaro, el periquito; según el diccionario de Seco la frase designa a "un hombre que gusta estar siempre entre mujeres" (SECO 2006: 776). Además, un periquito es bonito y canta bien, por tanto, un hombre representado por este dominio fuente es un hombre atractivo con una habilidad verbal bien desarrollada, así que es posible que, en algunos casos, el hombre al que se hace referencia mediante esta unidad pueda considerarse hasta embaucador. Con respecto a estas frases, aunque en muchos casos será así, no se puede decir que sean percibidas como positivas, sino que más bien dependerá de la situación en la que se empleen.

Hemos observado que entre las unidades españolas aparece con bastante frecuencia el tema de la homosexualidad de los hombres, mientras que entre las unidades checas no. En español las alusiones encontradas en el corpus que hacen referencia a 
la homosexualidad tienen como dominio fuente un pájaro: (15) canario flauta; (16) más que un palomo cojo/ palomo cojo. La primera unidad (15) utiliza como dominio fuente al canario, un pájaro típico por su color amarillo (que puede considerarse extravagante, sobre todo en relación con un hombre). Por su parte, el ejemplo (16) hace alusión a la homosexualidad mediante la palabra palomo. Es interesante que la forma léxica genérica de este animal es paloma, de género femenino. En este caso es probable que la forma masculina de esa palabra se haya empleado para hacer más saliente el hecho de que los homosexuales son percibidos, en la sociedad, como versiones masculinas de mujeres. En estas unidades podemos observar la intención de cuestionar la masculinidad de sus referentes.

En cuanto a las unidades que tienen como dominio fuente un pájaro, no podemos pasar por alto las alusiones a los órganos genitales de los hombres (aunque no se trate exactamente de la metáfora "los hombres son animales"). En ambos idiomas han surgido metáforas que tienen como dominio fuente el pene y cuyo dominio meta es un pájaro: (17) Podle nosa poznáš kosa; (18) cambiarle el agua al canario; (19) comer la polla. Encontramos un mirlo (kos) en la unidad (17), un canario en la (18) y una polla en la (19). El proverbio checo (17), cuya traducción podría ser 'según la nariz reconoces al mirlo', tiene como propósito indicar que según el tamaño de la nariz puede estimarse el tamaño del pene. La unidad (18), que hace alusión al canario, se refiere a la micción. La última UF (19) se refiere directamente al acto de la felación mediante el dominio fuente polla que, asimismo, es una denominación para el pene y una forma léxica poco común por lo que se refiere a la relación con aves.

En español hay otras unidades con connotación sexual que tienen como propósito cuestionar la masculinidad de los hombres (aunque no se trate de metáforas explícitas "los hombres son animales"): (20) hacer la vaca (a alguien); (21) poner rabos / un rabo. La definición de la unidad (20) en Seco: "dejar(le) por broma y a la fuerza, los genitales al aire y ensuciárselos con saliva, barro o excrementos" (SECO 2006: 1009) habla por sí misma. En lo que se refiere a la unidad (21), la definición es "sodomizar a un hombre" (SECO 2006: 860) y también se hace alusión a la homosexualidad, es decir, que al pene suele llamársele rabo, lo que también ocurre en checo (aunque ni la publicación de Mrhačová ni el diccionario de ČERMÁK (2009) lo han confirmado).

\subsubsection{Otras características del hombre}

Aparte de las abundantes unidades con connotación sexual, hemos podido observar unidades que contienen la metáfora directa "los hombres son animales" cuyo propósito es comentar las habilidades, la agresividad, la astucia o el aspecto de los hombres.

Entre estas, las más frecuentes son las que hacen comentarios acerca de la agresividad o la fuerza de sus referentes: (22) chlap jako gorila; (23) ponerse gallito. La primera (22) presenta el dominio fuente gorila (gorila); mediante la comparación de un hombre con este primate se hace alusión a su gran tamaño y fuerza (a pesar de que, en checo, el dominio fuente es femenino). En lo que se refiere a la unidad (23), esta tiene como dominio fuente un ave, el gallo, también famoso por su agresividad; además se halla en forma diminutiva con el propósito, probablemente, de ridiculizar al referente. 
En ambos corpus hemos encontrado unidades de alguna manera conectadas con las habilidades o la astucia de los hombres: (24) To je ale kos!; (25) zorro viejo; (26) pájaro de cuenta. La primera unidad (24) tiene como dominio fuente un pájaro: mirlo (kos); su propósito es hacer un comentario acerca la destreza e inteligencia de su referente. El estereotipo focalizado de la unidad con el dominio fuente zorro (25) podría definirse como la astucia; además, en esta unidad lo observamos en combinación con la edad avanzada, lo que hace alusión a la experiencia del referente. La última unidad (26), con un pájaro como dominio fuente, se refiere a un hombre "sinvergüenza o de cuidado" (SECO 2006: 721). En cuanto a las UF checas (27) y (28) -(27) lev salonů; (28) to je ale potápka- parece que su intención sería comentar el estilo de vida o el estilo de vestirse de sus referentes. La UF (27) tiene como dominio fuente un león $(l e v)$ y quiere describir a un hombre "elegante" que tiene una rica vida social. La frase (28) utiliza como dominio fuente un pájaro, el somormujo lavanco (potápka), y suele emplearse para describir a un muchacho joven de pelo largo. En esta frase podemos observar que se utiliza un dominio fuente que tiene género femenino, creemos que la razón para esto es subrayar que los hombres con el pelo largo son afeminados.

Aparte de las características mencionadas arriba, es posible encontrar en las unidades del idioma checo otros rasgos como es el orgullo y la estupidez: (29) Pro jednoho osla tráva nevyrostla; (30) Ten starý (dobrý) vưl/ Já starý vůl. En la unidad (29) se describe una situación en la que una chica es abandonada por su novio. Se hace una alusión al hombre que la ha abandonado mediante el dominio fuente burro (osel), un animal considerado (aparte de otras características) estúpido, y eso para quitarle la importancia a este y darle así consuelo a la chica. En la unidad (30) se observa una alusión al hombre como buey (vi̊l) y describe su excesiva bondad, que puede llegar hasta a la estupidez; sabemos que el buey es un toro sin testículos, así que es muy probable que esta unidad quiera implicar que un hombre "bueno" es un hombre poco masculino (quizá porque muestra demasiado sus sentimientos).

\subsection{Unidades flexibles}

En esta sección hemos analizado unidades fraseológicas relacionadas con animales que contienen las metáforas "los hombres son animales macho/hembra" y "las mujeres son animales macho/hembra" en diferentes combinaciones. Ya que el empleo de las unidades es ambiguo con respecto al género de los dominios meta, hemos estructurado el análisis según la naturaleza de los focos cognitivos, concentrándonos en la intención de algunas de las variantes, sobre todo las variantes "los hombres son animales hembra" y "las mujeres son animales macho".

En este momento queremos aclarar que se trata de unidades en cuanto a las que no se viola su estructura semántica al emplear dominios meta de diferentes géneros porque el empleo ambiguo realmente está aceptado y es comprensible por los hablantes. En otras palabras, es posible emplear una unidad ambigua como este hombrelesta mujer está hecho/a un toro; sin embargo, a la hora de emplear de la misma manera una unidad que solo puede ir con un referente representado por solo uno de los géneros-como sería el caso de este hombre es una pájara pinta- la unidad se hace incomprensible. 


\subsubsection{Agresividad y furia}

En lo que se refiere a las características de la agresividad y la furia, la mayoría de estas puede hallarse en unidades que, según los diccionarios, pueden emplearse de ambos modos, tanto en metáforas con el dominio meta masculino como en las del dominio meta femenino. No obstante, ya que estas características son consideradas típicamente masculinas creemos que las formas más frecuentes serán aquellas con el dominio meta de género masculino, algo que también puede observarse gracias a los ejemplos del empleo real que se incluyen en los diccionarios. Esto indica que, a la hora de emplear estas unidades con referencia a una mujer, su propósito será destacar alguna característica suya no correspondiente con el estereotipo y subrayar así su masculinidad, como por ejemplo en la frase está hecha un toro (es fuerte) o ta ženská řádí jako rozzuřený býk (es agresiva).

Las UF que contienen el estereotipo focalizado agresividad o furia en checo suelen tener como dominios fuente animales macho (toro, caballo, gato, gallo, tigre y perro); son las siguientes: být rozzuřený jako býk, řádit jako rozzuřený býk, řvát jako tur, kopat kolem sebel být jako spašený kůn̆, ježit/ naježit vousy jako kocour, prskat jako kocour, škrábat jako kocour, být bojovný jako kohout/ být bojovný kohout, (být) (jako) dva kohouti na smetišti, řádit jako tygr, zuřit jako tygr, (být) vzteklý jako pes, rvát se jako psi.

Igualmente, en español se trata, en general, de animales macho, aunque también aparecen dominios fuente de género femenino como fiera o bestia: hecho un basilisco (o como un basilisco), como una fiera (o hecho una fiera), como un toro (o hecho un toro), mala bestia (o bestia parda)

\subsubsection{Gran tamaño, fuerza y trabajo}

Las unidades que denotan gran tamaño y/o fuerza -conectadas generalmente con el trabajo- suelen relacionarse con lo masculino, ya que la sociedad percibe el trabajar -especialmente el trabajo físico duro- como una actividad típica de los hombres (VALDROVÁ 2006). En checo podemos observar unidades cuyos dominios fuente son animales macho, sobre todo los del ámbito doméstico utilizados para el trabajo en el campo, como el buey, el caballo y la mula. Aparte de estos, podemos observar una alusión a la hormiga (en checo, mravenec, de género masculino) que se considera un insecto trabajador, como dominio fuente. Al final, aparece un único dominio fuente femenino en este grupo, la yegua: být zapřažený jako vůl, být zedřený jako vưl, být zedřený jako drožkářská kobyla, být uštvaný jako kůn̆, být zapražený jako kün̆, být zedřený jako kůn̆, (být) zedřený jako mezek, (být) pilný jako mravenec.

En español también hemos observado dominios fuente representados por animales machos del ámbito doméstico como el burro o el cabrón (forma léxica peyorativa de macho cabrío). Por su parte, el toro (a pesar de haber sido incluido en este grupo) más que el trabajo representa la fuerza como tal, ya que los toros se perciben de una manera diferente en la sociedad checa y española por razones culturales: hecho una bestia, burro de carga, trabajar como un cabrón, como un toro (o hecho un toro), trabajar como un burro. 


\subsubsection{Hombres y mujeres habladores y de poca confianza}

Consideramos muy interesantes las unidades que pretenden describir a hombres y mujeres que hablan excesivamente o que no son capaces de guardar un secreto, es decir, que son poco fiables. Según algunos expertos en los estudios de género, estas características suelen vincularse con el estereotipo de las mujeres (GOÑI 2008). En las unidades estudiadas observamos que sus dominios fuente son, efectivamente, de género femenino y que, en la mayoría de casos, se trata de pájaros o sus partes (probablemente por su característica de cantar); en checo štěbetat jako husy 'cotorrear como ocas', štěbětat jako sojky 'cotorrear como arrendajos' y slepiči prdelka 'culo de gallina'. En español, la UF con esta semántica es ser una cotorra / más que una cotorra. Podemos observar que el emplear estas unidades tendrá como propósito ridiculizar a los referentes, en el caso de hombres, además, se trata de una manera de feminizarlos, ya que se les adscribe una característica típicamente relacionada (y mal vista) con el estereotipo de mujer (VALDROVÁ 2006).

En cuanto a la poca confianza, esta viene descrita por la unidad checa brečet jako stará kráva cuya traducción podría ser 'llorar como una vaca vieja'. Según MRHAČOVÁ (1999), el propósito de esta unidad es describir a alguien que llora de una manera fingida y puede emplearse tanto con un dominio fuente masculino como femenino. Otra vez observamos un rasgo negativo frecuentemente relacionado con el estereotipo de la mujer, la falsedad y la falta de sinceridad (VALDROVÁ 2006).

\subsubsection{Inferioridad y obediencia}

La expresión de la inferioridad es muy importante en las unidades relativas a animales. En checo suele decirse koně chval teprve po mésíci a ženu po roce ('al caballo puedes alabarlo después de un mes, a la mujer después de un año'). En esta unidad con la metáfora "género es específico" podemos observar cómo se sitúa a la mujer a un nivel aún más bajo que el de un caballo. En el caso de esta primera unidad, probablemente nos referiríamos solo a mujeres, sin embargo, en la unidad checa jít $z a$ nékým jako ovce za beranem ('seguir a alguien como la oveja al carnero') observamos la alusión a la obediencia, sin tener claro si puede tratarse solamente de un dominio meta femenino o si podría emplearse un referente masculino también.

En la unidad española ser el amo de la burra también podemos observar que se expresa la superioridad del amo (masculino) sobre la burra, de género femenino; no obstante, tampoco queda muy claro si en realidad los dominios meta pueden ser de ambos géneros.

\subsubsection{Cobardía y debilidad}

En los corpus también se han hallado unidades cuyo papel es subrayar la cobardía o la debilidad de los referentes. Estas unidades suelen tener como dominios fuente animales considerados débiles. En checo suele utilizarse como dominio fuente la cabra en su forma femenina como en být slabý jako kozy duch 'estar/ser débil como el fantasma de una cabra' o mluvit jako koza pred smrtí 'hablar como una cabra antes de la muerte'; otra posibilidad es el gorrión, que tiene forma masculina: mít sílu jako ženatý vrabec 'ser fuerte como un gorrión casado'. Otro pájaro, de género femenino en checo, es třasořitka (lavandera blanca), se documenta en la unidad Třasořitka 
jeden!, cuyo propósito es subrayar la cobardía de los referentes (también mediante el sufijo apreciativo $-k a$ ). En español podemos encontrar las siguientes unidades: como un conejo o cantar la gallina. Sobre todo en el caso de emplear estas unidades con un referente masculino podemos observar la clara intención de cuestionar su masculinidad.

\subsubsection{Suciedad y borrachera}

En checo hemos observado muy frecuentemente alusiones a la borrachera y a la suciedad. Todas estas unidades presentan un dominio fuente masculino, como cerdo (prase) o jabalí (kanec). También aparece el dominio fuente gato, en español, aunque en este caso es importante añadir que no se trata exactamente de su suciedad, sino de su manera de lavarse, que es sin agua: být opilý / ožralý jako kanec, být špinavý jako kanec/ prase, smrdèt jako kanec, být opilý / ožralý jako svině, smrdět jako starý kozel. En español: como cerdo/a, a lo gato (o como los gatos).

\subsubsection{Pereza}

En checo también hace frecuentemente su aparición el ECF pereza. Al igual que en el caso de la suciedad y de la borrachera, pueden observarse muchos dominios fuente masculinos. Aparte del cerdo (prase) y el jabalí (kanec), hay dos dominios fuente femeninos: la gata (kočka) y la cerda (en checo svině, que se utiliza frecuentemente como insulto): být liný jako vepř, být linýjako kanec, být líný jako svině, válet se někde jako ta svině, ráda kočka ryby jí, ale do vody se ji nechce, lidští trubci.

\subsection{Animales con el género marcado}

A continuación queremos observar cómo se reflejan los roles sociales en unidades que contienen animales que tienen el género marcado. Nos centramos, por tanto, en los estereotipos conceptuales focalizados de las unidades que contienen este tipo de animales. Al llevar a cabo esta parte del análisis había que tener en mente que hay rasgos que suelen ser adscritos a ciertos animales gracias a su comportamiento sin hacer diferencias entre los géneros. No obstante, y pese a esto, hemos podido observar casos en los que hay una diferencia más que clara entre un género y el otro; además, en muchos casos hay rasgos que comparten ambos géneros de un animal, mientras que otros se adscriben solo a uno de ellos.

Al observar los resultados de este análisis también hay que tener en cuenta los de los análisis anteriores, que indican cuáles suelen ser las intenciones de los hablantes al emplear ciertas unidades -como por ejemplo subrayar un rasgo masculino en un hombre o adscribir un rasgo masculino a una mujer, y al revés-, de modo que, aunque a veces no parece existir gran diferencia en la percepción de los dos géneros de un animal, en realidad, al emplear las unidades en la práctica puede ocurrir un desequilibrio respecto al género gracias a la naturaleza de los dominios meta y fuente y de las propiedades semánticas del estereotipo focalizado que, a primera vista no se percibiría. 


\subsubsection{Checo}

Hay denominaciones de animales con el género marcado léxicamente respecto a las que no cabe hablar de gran diferencia como, por ejemplo, el caballo y la yegua (kůn̆/hřebec, klisna/kobyla), ya que ambos suelen ser percibidos como animales grandes y que trabajan excesivamente, sin mucha diferencia entre los géneros. El perro y la perra (pes/čokl, fena), en la gran mayoría de casos, suelen ser representados como inferiores y con una vida miserable, además de agresivos o malos; de nuevo, sin mucha diferencia entre los géneros. En lo relativo a los dragones (drak, $s a n ̌)$, en ambos casos son agresivos y peligrosos. También la oveja y el carnero (ovce, beran) son percibidos por los hablantes checos como animales testarudos, estúpidos y obedientes; la única diferencia que puede observarse es que a las ovejas se las suele considerar más estúpidas y obedientes, mientras que a los carneros más testarudos.

Sin embargo, en otras parejas de animales puede observarse una diferencia considerable en cuanto a la percepción de los géneros, como, por ejemplo, la gallina y el gallo (slepice/kvočna/kura, kohout); así, la gallina en checo suele percibirse como estúpida y habladora, mientras que al gallo se lo considera un animal agresivo y competitivo. Por lo que se refiere al cerdo y a la cerda (vep̌r/kňour/kanec, svinè), el rasgo que tienen en común es la pereza y la suciedad; al cerdo masculino además suele adscribírsele la borrachera, la agresividad o la potencia sexual, mientras que a la cerda más bien la malicia. El caso del toro y de la vaca en checo (býk/vůl/tur, kráva) es parecido al del cerdo, ambos se perciben como fuertes y grandes, sin embargo al toro, además, es relacionado con la agresividad y la potencia sexual, mientras la vaca con la estupidez y la gordura. El ciervo (jelen) se percibe, en checo, como grande y orgulloso, mientras a su pareja, la cierva (lan̆), se la ve como tímida y frágil. La abeja (včela) se considera trabajadora en comparación con su pareja, el zángano (trubec), al que se considera perezoso según los estereotipos conceptuales focalizados de las unidades documentadas.

Respecto a los pares formados mediante sufijos, hemos observado algunos animales que no muestran grandes diferencias. Entre aquellos cuya palabra base es masculina está el pavo real (páv, pávice), animal al que se le adscribe la característica orgullo. En materia de tigres y los leones (tygr, tygřice; lev, lvice), asimismo, se trata de palabras genéricas de base masculina; sus características típicas son la agresividad, la valentía y el peligro que significan para los humanos. La paloma y el palomo (holub, holubice) en checo tienen una base masculina (holub) que sería el prototipo de animal enamorado mientras que a su pareja (holubice) se la relaciona con la tranquilidad y se la considera un ser manso.

Entre los animales cuya palabra genérica es femenina encontramos el gato (kočka, kockour). Sus características generales son la astucia, la agresividad o la buena vista; además, a las gatas exclusivamente se las suele relacionar con la falsedad. La cabra y el macho cabrío ( $k o z a, k o z e l)$ se ven como animales estúpidos, torpes y malolientes; a las hembras se las relaciona además con la debilidad y la estupidez. Un caso parecido podemos observarlo en la oca y el ganso (husa, houser), dado que la oca se percibe como estúpida, mientras que el ganso, en la fraseología checa, se relaciona con una enfermedad (houser). También en la pareja pavo (kro- 
can) y pava (krůta) la hembra se percibe como estúpida mientras el macho como agresivo. Al observar las denominaciones para zorros (liška, lišák), observamos que su mayor rasgo es la astucia, sin diferencias entre los géneros. Por último, en cuanto al mono (opičák) y la mona (opice), los rasgos salientes en ambos géneros son la astucia y la inteligencia.

\subsubsection{Español}

En el corpus de UF españolas se ha hallado solo una pareja de animales que se caracterizan por tener dos palabras distintas en cuanto a cada uno de los géneros: la vaca y el toro. En lo que se refiere a estos, el toro es un animal que en España tiene una fama especial debida a su importancia en la vida cultural, siendo un animal orgulloso, fuerte y agresivo; la vaca, por su parte, suele relacionarse con la gordura.

El resto de las denominaciones que hemos estudiado han sido las formadas mediante sufijo. La mayoría tiene como base un sustantivo de género masculino. Igual que en checo, no hay mucha diferencia respecto al león y la leona o el tigre y la tigresa, todos ellos son animales agresivos y valientes. El burro y la burra, generalmente, se perciben como animales que trabajan mucho. En el diccionario tampoco hemos documentado que se perciban de una manera diferente el zorro y la zorra, los dos se describen como astutos. El perro y la perra tienen una situación parecida a la del checo, ambos inferiores y pobres. Ya se ha comentado antes que la palabra zorra (al igual que perra) se utiliza en español para insultar a una mujer, como sinónimo de prostituta; sin embargo, el diccionario de Seco no lo recoge. El cerdo y la cerda se perciben como gordos y sucios. El bicho y la bicha, derivada de este, se consideran seres maliciosos y repulsivos, de modo que no hay mucha diferencia. Por el contrario, en lo relativo al conejo, que es representado como un animal indefenso, y la coneja, que se relaciona con la excesiva fecundidad, obviamente, observamos diferencia. Por otra parte, mientras al pollo, aunque aparece en las unidades, no se le adscribe ninguna característica especial, su pareja, la polla, se documenta en varias unidades en referencia al pene. El pavo y la pava también son un caso en el que una de las denominaciones, la pava, no tiene ninguna característica específica, mientras el pavo se percibe como un ser de poca experiencia. En las unidades fraseológicas estudiadas, el pájaro se relaciona con un sinvergüenza, mientras la pájara, derivada de él, suele hacerlo con alguien frívolo. La última pareja es la formada por el mono y la mona; el mono se percibe como insignificante y la mona como demasiado extravagante.

Por último, respecto a las parejas de animales cuyas palabras genéricas son femeninas, cabe destacar que el rasgo más relacionado con la cabra es la locura, mientras que cuando se utiliza la palabra cabrón -que, además, hoy día más que una denominación para llamar el macho cabrío, es un insulto- lo que se destaca es un nivel alto de intensidad (relacionada sobre todo con el trabajo). Observamos diferencia entre la percepción del gallo, que se considera agresivo, y la gallina, que se relaciona con los rasgos de cobardía y poca confianza (al igual que en checo). El palomo, una forma léxica poco utilizada derivada de la (mucho más frecuente) paloma, se relaciona con la falta de masculinidad y la homosexualidad; por su parte, la paloma aparece con el estereotipo focalizado bondad. 


\section{Conclusiones}

El trabajo que presentamos tenía como objetivo analizar unidades fraseológicas checas y españolas relativas a animales desde el punto de vista de la lingüística cognitiva y los estudios de género para observar y comparar cómo se perciben los roles sociales del hombre y de la mujer dentro de estos dos entornos culturales.

Una primera y necesaria advertencia se refiere a que el tamaño, e incluso la propia naturaleza, de los corpus empleados se diferían y, por ello, los resultados pueden presentar cierto desequilibrio. Aun así, los consideramos suficientemente representativos porque el mayor propósito del análisis ha sido obtener, ante todo, un reflejo de naturaleza cualitativa.

El análisis se ha dividido en tres partes. El objetivo de la primera parte ha sido estudiar de un modo general el reflejo del hombre y de la mujer en la fraseología relativa a animales. Respecto al género femenino hemos documentado que en las unidades fraseológicas checas este suele relacionarse con la estupidez, mientras que en el contexto español aparece frecuentemente la característica de locura y molestia. En lo que se refiere a las características masculinas, tanto en checo como en español aparecen en los primeros escalones la agresividad, la fuerza y el gran tamaño, aunque en español el rasgo más frecuente de todos es la rapidez. También es bastante sorprendente la aparición frecuente de las características de pequeño e insignificante respecto a los hombres en español.

En la segunda parte se han analizado las unidades concretas que contienen las metáforas "las mujeres son animales", "los hombres son animales" y "los hombres/las mujeres son animales". En cuanto a unidades que solo pueden tener como referente a una mujer, las hipótesis se han comprobado en un alto grado. Es decir, se ha documentado, en ambos idiomas, un grupo numeroso de unidades que valoran el aspecto físico de las mujeres (con alusiones positivas a la delgadez y negativas a la gordura); además, aparecen frecuentemente los temas del sexo (con estereotipos focalizados relacionados con la frivolidad o la dudosa moral, negativamente percibidas), la edad y la maternidad. Otra temática bastante frecuente que, en cambio, no se corresponde con el estereotipo de la mujer, es el trabajo positivamente valorado en checo. Además, en comparación con el español, en checo se han documentado como muy frecuentes unidades con el estereotipo focalizado timidez y estupidez.

En cuanto a las metáforas que solo pueden referirse a hombres, no son tan numerosas y el tema más frecuente al que hacen alusiones en ambos idiomas es el sexo. Hay muchas unidades que valoran de una manera positiva la actividad y la potencia sexuales de los hombres, utilizando como dominios fuente animales macho. También se han documentado unidades que comentan las habilidades, la agresividad o la astucia de los hombres. Al contrario que en checo, en español aparece el tema de la homosexualidad masculina valorada de una manera negativa.

En el caso de las unidades con un dominio meta ambiguo hombre/mujer (dependiendo del contexto), las hipótesis se corroboraron de una manera más clara. Hemos podido observar que cuando cambiaba el género de los dominios meta también cambiaban las intenciones de los hablantes al emplear las unidades, es decir, las de mar- 
car la correspondencia o no correspondencia con el rol social. Por tanto, en la mayoría de los casos en que se empleaba una unidad cuyo dominio fuente y meta coincidían en el género, se marcaba un rasgo correspondiente con el estereotipo; mientras que, en el caso opuesto, se hacía referencia a una anomalía que solía ser valorada negativamente (algo especialmente patente cuando se trataba de dominios fuente femeninos referidos a hombres, ya que hemos observado que el elemento femenino se considera menos valioso). Se trataba, por ejemplo, de casos en que se expresa la fuerza, la agresividad y la excesiva libertad de las mujeres mediante dominios fuente masculinos o la debilidad, la afeminación o la charlatanería de los hombres mediante dominios fuente femeninos.

El objetivo de la última parte del análisis era observar si hay diferencias en la percepción de los roles sociales en animales que tienen el género marcado mediante denominaciones diferentes de los dos géneros o cuyas denominaciones de los géneros han sido derivadas mediante sufijos. Por un lado, hemos documentado el hecho de que a la mayoría de los animales suelen adscribírseles características que, de alguna manera, corresponden a su naturaleza (o a la manera de percibirlos por las sociedades) y no se hace diferencia entre los géneros. Sin embargo, hay animales respecto a los que sí pueden observarse asimetrías. Estas asimetrías suelen ser generalmente de tal naturaleza que las denominaciones para los machos (como toro/býk, gallo/kohout, cerdo/kanec) suelen utilizarse para hacer referencia a acciones no tan negativamente percibidas por los hablantes, es decir, tienen una carga más positiva que la de sus parejas (vaca/kráva, gallina/slepice o cerda/svině), que llevan una carga más negativa o/y pueden utilizarse directamente como insultos. De esta manera se vuelve a comprobar el hecho de que, en muchos casos, el elemento femenino se considera inferior al masculino.

$\mathrm{Al}$ resumir los resultados del análisis podemos observar, aparte del hecho de que las hipótesis que se habían propuesto se han comprobado en un alto grado, que las unidades fraseológicas relativas a animales disponen de una alta capacidad para reflejar la manera de percibir los roles sociales del hombre y de la mujer en las sociedades checa y española. Creemos indiscutible el hecho de que ambas sociedades se caracterizan por tener arraigado dentro de ellas un desequilibrio notable entre los hombres y las mujeres y que hay una tendencia fuerte hacia la discriminación de ambos géneros (siendo la discriminación de las mujeres mucho más frecuente). Sin embargo, a causa de que los corpus difieren en tamaño, e incluso en los principios fraseográficos según los que se han realizado, consideramos imposible presentar conclusiones sobre la medida en la que ocurren estas asimetrías y desequilibrios para poder comparar si, dentro de una de las sociedades, hay más tendencias discriminatorias ante los géneros que dentro de otra.

\section{Referencias bibliográficas}

ČERMÁK, F. (2009): Slovnik české frazeologie a idiomatiky, Leda, Praha. CORPAS PASTOR, G. (1996): Manual de fraseología española, Gredos, Madrid. 
DOBROVOL'SKIJ, D., PIIRAINEN, E. (2005): Figurative Language: Cross-cultural and Cross-linguistic Perspectives, Elsevier.

DOYLE, J. (1991): Sex and Gender: The Human Experience, William C. Brown Publishers. EISNER, P. (1992): Chrám i tvrz, Vydavatelství Lidových novin, Praha.

GOÑI, C. (2008): Lo femenino, Ediciones Universidad de Navarra, s. a., Pamplona.

GUTIÉRREZ RUBIO, E. (2012a): “Aproximación al estudio cognitivo plurilingüe de la fraseología como imagen del mundo", en Lingüística XL. El lingüista del siglo XXI, SEL ediciones, Madrid, pp. 87-91.

GUTIÉRREZ RUBIO, E. (2012b): “Colours and Linguistic Picture of the World", en Beiträge der Europäischen Slavistischen Linguistik. (Polyslav) Band 15, Verlag Otto Sagner, Múnich, pp. 104-108.

GUTIÉRREZ RUBIO, E. (2013a): “Fraseología y estereotipos en español. ¿Una relación bidireccional?", Language Design, vol. 15, pp. 119-136.

GUTIÉRREZ RUBIO, E. (2013b): “La valoración de 'el otro' en la fraseología Alemana, checa, española e inglesa", Études romanes de Brno, 34/2, Masarykova univerzita, Filozofická fakulta, Brno, pp. 149-169.

HELLINGER, M. (2002): Gender Across Languages: The linguistic representation of women and men, John Benjamins, Philadelphia.

IBARRETXE-ANTUÑANO, I., VALENZUELA, J. (2012): Lingüística cognitiva, Anthropos Editorial, Barcelona.

KEKIĆ, K. (2008): “El lenguaje figurado con zoónimos en serbio”, Language Design, vol. 10, pp. 107-131.

KIMMEL, M. (2011): The Gendered Society, Oxford University Press, Oxford.

LAKOFF, G., JOHNSON, M. (2002): Metafory, kterými žijeme, Host, Brno.

LAKOFF, G., \& TURNER, M. (1989): More than Cool Reason: a Field Guide to Poetic Metaphor, The University of Chicago Press, Chicago.

LUQUE NADAL, L. (2012): Principios de culturología y fraseología españolas, Peter Lang International Academic Publishers.

MRHAČOVÁ, E. (1999): Názvy zvírat v české frazeologii a idiomatice (tematický frazeologický slovník I), Facultatis Philosophicae Universitatis Ostraviensis, Ostrava.

OAKLEY, A. (2000): Pohlaví, gender a společnost, Portál, s. r. o., Praha.

SECO, M. (2006): Diccionario fraseológico documentado del español actual: locuciones y modismos españoles. Santillana, Madrid.

SORIANO, C. (2012): "La metáfora conceptual”, en Lingüística Cognitiva, Anthropos, Barcelona, pp. 97-121.

TIMOFEEVA, L. (2012): El significado fraseológico. En torno a un modelo explicativo y aplicado, Liceus, Madrid.

VALDROVÁ, J. (2006): Gender a společnost, UJEP, Ústí nad Labem.

VALDROVÁ, J. et al. (2004): Př́ručka pro posuzování genderové korektnosti učebnic, Praha. 